\title{
Research on the Design of Artistic Derivatives Based on Optimizing Emotional Experience*
}

\author{
Xiaotao $\mathrm{Hu}$ \\ Communication University of China \\ Beijing, China 100024
}

\author{
Zhiqiang Dai \\ Communication University of China \\ Beijing, China 100024
}

\begin{abstract}
Emotional experience is the decisive factor for artistic derivatives to survive in the market. The design of artistic derivatives should regard the prioritization of the emotional experience as the core element. First of all, the arrival of the era of great aesthetical economy has determined the importance of emotional experience. Consumers purchase commodities to satisfy the emotional appeal. The experiential consuming behavior shows the consumption field is expressing the requirements to identify, adore and long for art. In the second place, the attributive character of artistic derivatives has determined the importance of emotional experience. Artistic derivatives are "user-friendly artworks". The creation process of artistic derivatives is exactly the same as that of art. The emotional experience has always accompanied the process to create artistic derivatives. In addition, the psychology of consumers of artistic derivatives has also determined the importance of emotional experience. The design of artistic derivatives should take the prioritization of consumers' emotional experience as the highest guiding principle.
\end{abstract}

Keywords-emotional experience; artistic derivatives; design research

\section{INTRODUCTION}

With the rising of cultural industry, artistic derivatives have attracted people's unprecedented attentions. As a media for culture in mass communication, artistic derivatives are the most crucial links of value creation in cultural industry chain, and its ability of value creation is always several times of cultural products themselves ${ }^{[1]}$. For example, only 20 percent revenue in the total revenue of American film industry comes from screen marketing, while the rest 80 percent revenue derives from the development of film derivatives. However, a gap always exists between theory and practice, just as the gap eternally existing between ideal and reality. The sales status of derivatives at home is below expectation and far from reaching the ideal value. Taking domestic movie and television play as an example, its primary income still depends on box office and product placement, and the development and design of its subsequent derivatives is still the weak link ${ }^{[2]}$. It requires us to ponder the reason, the consumer market of derivatives is

\section{*CLC No.: J505 Document code: Paper ID:}

The research is subsidized by the project of strengthening universities via innovation in Guangdong Province (GDOU2015050246) and the special fund project for the construction of service platform of medium small and microsized enterprises in professional towns of Guangdong Province (2013B040500022) immature, or the design and manufacturing level of them is far from perfect. Some scholars reckon the main reason why the consumer market of domestic artistic derivatives is sluggish is that the artistic culture of Chinese people should be improved urgently. However, the consumption of derivatives needs guidance, and the artistic derivatives are also responsible for spreading culture and training people's artistic culture. Therefore, the key to the problem is still whether the design of derivatives can meet the potential requirements of Chinese people and has foresight to some extent at the same time stimulates the purchasing desire of consumers. The emotional experience is the core factor for consumers to purchase artistic derivatives, so the design of artistic derivatives should center on prioritizing emotional experience.

\section{EMOTIONAL EXPERIENCE}

In the research on user experience, the emotional value refers to a king of feeling of users in using products, systems or services and an important factor of user experience. Hekkert (2016) thinks user experience is the result of the interaction between users and products, including the sensory satisfaction degree (aesthetic experience), the sense of belonging of value (value experience) and emotional feelings (emotional experience). The emotional experience is the highest form of user experience and also one of the major directions for the research on user experience in the future ${ }^{[3]}$. The research of Zhang Chengzhong and Yang Jinzhong (2009) has pointed out if the users are pleasurable, they will be inclined to tolerating and neglecting other problems in design. For example, when people purchase MiniCooper, they will neglect the defects of the vehicles, because its interestingness is touching and lets people neglect its defects ${ }^{[4]}$. As shown in Fig. 1, the designer Philip Stark addresses his representative work, the juicer "Juicy salif", is only a sculpture instead of a home appliance with utility functions. The purpose of its existence is not to juice but to cause new topics of people's conversation. There are three alternative colors of the product. The instructions of gold-plated juicer further emphasize users should use it carefully because the acidic materials of lemon or orange juice will have corrosive effect on the gold-plated layer. It further verifies the opinion of the designer. However, the consumers that are keen on the juicer are completely attracted by its elegance and novelty and find a strong emotional experience on it so that they totally neglect its use value. It is more like an artwork than a home appliance, just as Norman mentions in the book of Emotional Design, "the affective component contained 
in design may be more important than the practical component for the success of products". The above-mentioned have explained the importance of emotional experience, verified the emotional experience is the highest form of user experience. Under some circumstances, it outmatches the experience at other levels.

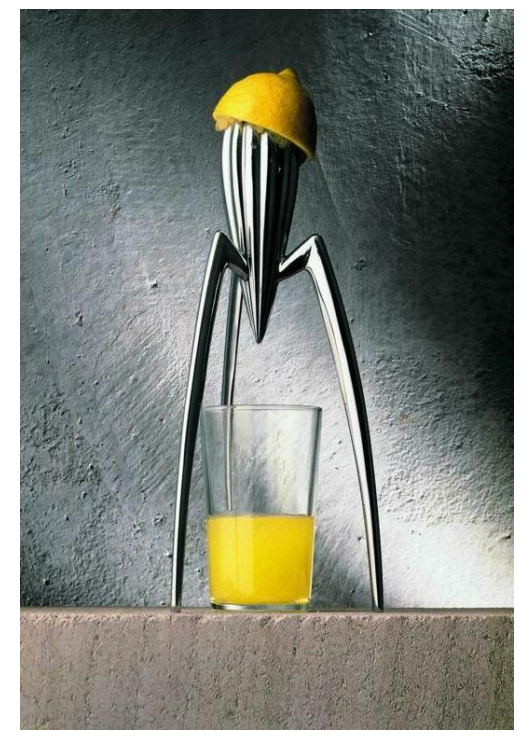

Fig. 1. "Juicy salif” Juicer / Designer: Philip Stark.

In the field of cognitive psychology, emotional experience is individuals' subjective experience of emotions, including not only the emotional contents experienced by individuals but also the experiential process of them and emphasizing the unification between emotional contents and experiential process ${ }^{[5]}$. Psychology researchers Schwarz and Clore (1996) address people's emotion is also a source of information when people draw conclusions. People simplify the task of judgment directly via inquiring their feelings toward things. Therefore, in fact, some evaluations and judgments are peoples' emotional response to things ${ }^{[6]}$. For example, people always have several standards such as stature, weight and family background for their future couples before encountering the ones admired by them, but many people find the couples found by them are far cry the so-called standards, it is because the majority regard the emotional response as the major evaluation standard in the judgment process. The psychologist Antonio Damasio (2000) puts forward the eight main characteristics of emotional experience: 1 . emotional experience is primary; 2. emotions are the most fundamental response of living nature; 2. emotional experience is very difficult to control; 4. no right or wrong emotional experience exists; 5. emotional experience expresses self-feelings; 6 . it's difficult to describe emotional experience perfectly; 7 . emotional experience does not rely on cognition; 8. emotional experience and experiential contents are separable ${ }^{[5]}$.

\section{PRIORITIZING EMOTIONAL EXPERIENCE IS THE CORE FACTOR FOR THE DESIGN OF ARTISTIC DERIVATIVES}

\section{A. The Coming of the Era of Great Aesthetical Economy Has Determined the Importance of Emotional Experience}

The global economy has entered a new era namely the era of great aesthetic economy since 1960s. The so-called great aesthetic economy means the economy integrating utility and aesthetics, product and practice replaces the traditional economy that emphasizes products' utility function and general services ${ }^{[7]}$. The Experience Economy frequentlymentioned by people is the symbol that the great aesthetic economy emerges. Scholar Payne thinks the Experience Economy refers to an economic form that enterprises attract consumers' attentions through taking service as the stage, commodities as props and experience provision as output ${ }^{[8]}$.

In this era, people's purchase of a commodity is not a pure rational consumption behavior but an experiential consumption behavior, which can be understood at two levels. First of all, when consumers buy products, they by no means rationally consider products' practical value and functional value but pursue emotional appeal. The personal preference determines whether they will purchase it or not. Therefore, consumers pay more attention to the emotional commodities that resonate with their psychological needs ${ }^{[9]}$. The symbol value and cultural connotation of these products conform to perceptual factors such as their individuality, taste, self-esteem, ego, social status and value, which are significant components of emotional experience. In the second place, consumers pay attention to not only products or services themselves but also the whole consumption process. That's to say, they attach importance to the experience feeling of the whole consumption process. For example, fresh fruits can be purchased directly at supermarkets, but now consumers are willing to spend more money and time in picking personally in orchards in outskirts, which is to experience the whole consumption process ${ }^{[10]}$. The brand of IKEA has won a large number of loyal consumers that enjoy the experience process of consumption via elaborately establishing this kind of process.

The experiential consumption behavior is particularly dominant in the field of culture and art. The consumption of the mass to a large extent is to express their identification and admiration of art and their yearning needs of possession ${ }^{[11]}$. Therefore, people purchase more an artwork that stimulates their emotional resonance and interaction than an artistic derivative. The purchase of derivatives enable us to contact the artistic beauty of the original artworks in a new way, experience and taste the wonderful journey of culture and art again, then further extend the splendid experience. It will meet our emotional needs and the needs for artistic beauty and manifest our cultural taste ${ }^{[11]}$. At the meantime, these artistic derivatives are also unforgettable souvenir of artistic experience and bear people's pleasurable experience and memories, which are more precious than derivatives, such as cinema ticket, railway ticket, tickets even stones and leaves collected by people. The articles are valueless, but without them, the magnificent love experience may be forgotten, and the amazing journey of artistic visit will gradually disappear in our memory. More importantly, without these articles, it's 
impossible for us to show and narrate our beautiful experience to others, which is very pitiful ${ }^{[8]}$. All the above-mentioned feelings belong to emotional experience. Therefore, under the current historical background, the importance of emotional experience is self-evident.

\section{B. The Attributive Characteristics of Artistic Derivatives Have Determined the Importance of Emotional Experience}

In a broad sense, artistic derivatives have contained all the products that externalize the original artistic products into material forms, and the product range involved is very extensive. In a narrow sense, artistic derivatives refer to newtype cultural and creative products formed by designers who deeply understand and reconstruct the symbolic meaning, aesthetic characteristics, humanistic spirit and cultural elements of the original artistic products ${ }^{[12]}$ and take it as the major source of design inspiration. Artistic derivatives in a narrow sense can perfectly embody the level of creativity and design and are designers' recreation of artworks, the main power for value creation in the cultural industry and also the derivatives most insufficient in the current domestic market. It is the key field of derivative design and research.

According to the above definition, artistic derivatives in a narrow sense are designed by designers who base on market needs and positioning after fully understanding the spiritual connotation of artworks. At present, with the development of era, the boundary between design and art becomes increasingly vague. Design is striving to approach to art and manufacturing some commodities according to feelings, just like art does ${ }^{[13]}$. The more high-end and luxurious commodities present the tendency of becoming artworks to a larger extent. Meanwhile, becoming artworks further improves added value of these commodities. The art lamps of Serip, the Europe top brand of household lighting exhibited in the design exhibition in Beijing in 2015 are shown in Fig. 2. These lamps are made by lighting sculptors in Lisbon Portugal by hand, and they have very rich experience; Fig. 3 shows the renowned and international luxurious home furnishing brand, INSANE, which is mainly responsible for indoor and product design of hotels and customization field and is positioned on high-end users. It is adept at using personalized design language to interpret the unique household products and perfectly integrating the spiritual design and passionate hand making. It is difficult for us to accurately distinguish whether the art lamps and furniture as beautiful as sculptures according to the traditional concept. Artistic derivatives take artworks as the source of design inspiration from the very first. In the design process, designers' cognition, understanding and emotions incurred are also added. At the same time, the professional nature of designers makes them take the use of people into consideration. Therefore, artistic derivatives have always been on the boundary of art and design. Just as Taiwan designer Ye Yuxuan says, artistic derivatives are "user-friendly artwork". Only in an absorbed attitude can we create excellent artistic derivatives.

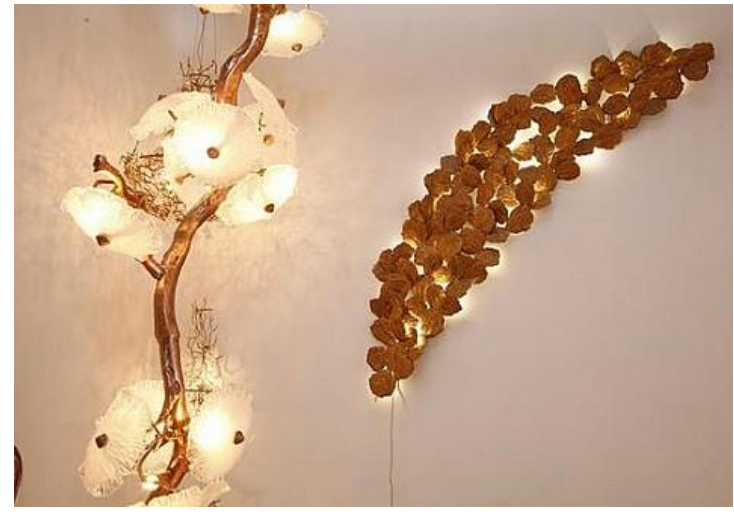

Fig. 2. SERIP Art Lamps / Source: This research.

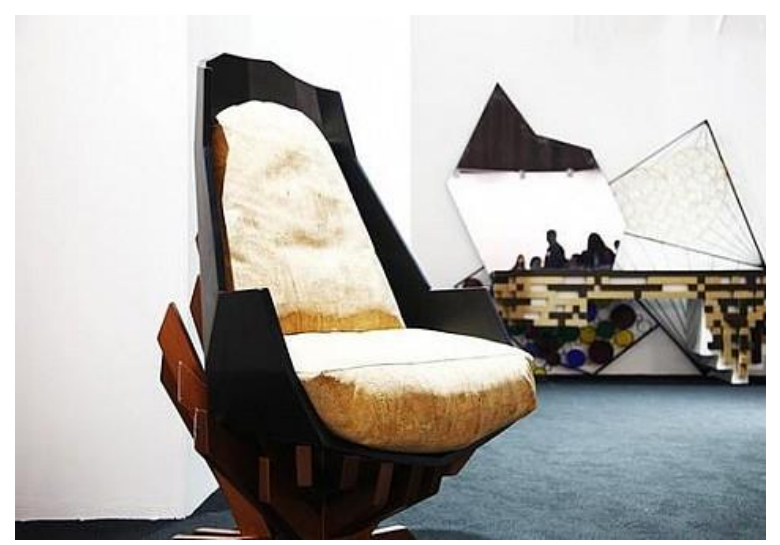

Fig. 3. INSANE art furniture / Source: This research.

The nature of art is emotion. All arts are created to manifest human emotions. Susan Lange observes "the purpose of art is to convey the insight of artists for human emotions", "art is an appearance form to manifest human emotions" [14]" What artistic expression abstracts is the part that can only be felt and grasped via instinct and cannot be told in the emotional life. She has further raised the essential process of artistic creation. She thinks just as the creative impulse of original artists mainly comes from expressive natural forms, artists have an original object in the original creation process. The original objects can be called the prototype of artworks. Artists create perceptual abstract objects with some artistic meaning through interpreting and handling the prototype again. Instead of simply copying or imitating of the prototype, the abstract object involves the reinterpretation and understanding of artists and manifests artists' emotions and feelings via having an insight into the nature of prototype. In essence, the creation process of artistic derivatives is exactly the same as the creation process of art. The difference is that the objects handled by artistic derivatives are artworks, and the final form to express emotions is objects designed. That is to say, what artistic derivatives manifest is the insight of designers for the nature of original artworks, and then they express the emotions and feelings via objects designed. It is evident that the emotional experience always accompanies the whole process of creating artistic derivatives. 


\section{The Consumption Psychology of Consumers of Artistic Derivatives Has Determined the Importance of Emotional Experience}

The consumers of artistic derivatives roughly consist of three types. In comparison, the first type of consumers is in the minority. Generally speaking, they have a good artistic accomplishment and a strong preference for some kind of art. They experience the beauty of original artworks in an alternative way, namely purchasing artistic derivatives, which make up for the pity that they fail to possess the original artworks and make them satisfied emotionally. The second type of consumers is the general publics who have certain artistic complex. They purchase artistic derivatives to memorize an unforgettable artistic experience or manifest their social status through consuming artistic derivatives. After all, artistic derivatives are relatively high-level consumption products and symbolize elegant taste. Consumers feel satisfied with the symbol value and its cultural connotation of artistic derivatives to manifest their individuality, taste and value, and have the opportunity to show or narrate their experience to others ${ }^{[8]}$. Consumers of the third type purchase artistic derivatives to bestow on others as gifts. In the industrial age, although products related to batch production greatly reduce the manufacturing cost, it is at the expense of lowering aesthetic feelings and lacking individuality. For consumers pursuing taste and individuality, it is never an easy thing to choose suitable gifts to send to esteemed guests or intimate friends. The importance of the gift is not the price but the elaboration and special meaning and certain cultural and artistic deposits, and it should fully express the kindly feelings of senders. Exquisite artistic derivatives can meet the emotional needs. It continues the essence of artworks and its price is reasonable for consumers.

Obviously, although having certain functions is one of the factors for the success of artistic derivatives on the market, the emotional experience is the factor that determines consumers' consumption of artistic derivatives. After all, people don't lack common tea sets or silk scarf but expect a tea set with cultural connotation and a silk scarf that continues the beautiful experience. People manifest their cultural tastes through consuming artistic derivatives, which meet their emotional needs for artistic beauty. The western tableware from the National Palace Museum, Taipei shown in Fig. 4 has fully integrated art and design. The inspiration of the derivative derives from the calligraphy Slender Gold created by Emperor Huizong of Song Dynasty. In the calligraphy, the chirography is slender and strong, and the writer should move swiftly. The character is extremely slender but doesn't loose the spirit. Designers bring the rigid but fluent oriental lines in the western tableware. The grab handle echoes with the end stroke of calligraphy and the handle with some thickness also complies with users' habits of the application of force.

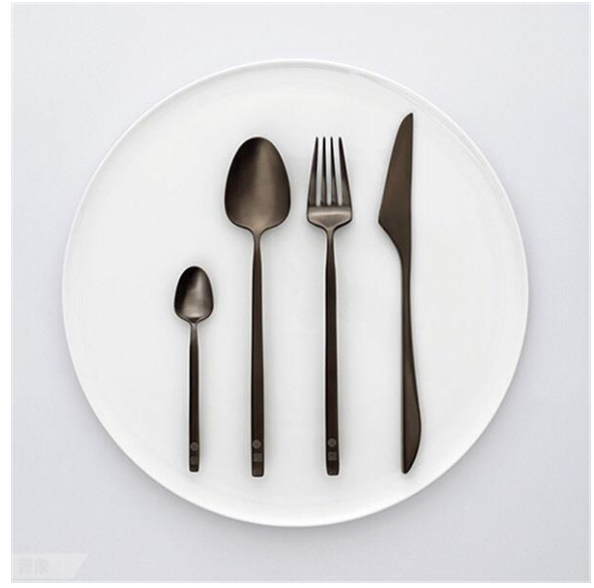

Fig. 4. Western tableware of calligraphy series of Slender Gold / Source: National Palace Museum, Taipei.

Take visitors of museums as an example. Nowadays, museum visitors have no longer been satisfied with the pure visit, research and learning. They expect to have more complete emotional experience. A planner of a complete experience starts with the advertising of museums in terms of the experiential process of museum. In this way, the objects in museums will stimulate people's curiosity. They begin to expect a close observation in the museum. The emotion will last throughout the process of formal visit. In the process of visit, the exquisite and elegant cultural image of objects, the environmental design, space atmosphere, facility layout, exhibit display, lighting effect and music selection in the museum will further enrich people's sensual experience, namely the experience of visual sense, auditory sense, smell, gestation and touch tactile sense. The above experiential process will be turned into spiritual satisfaction and leave deep memory. At that time, people will have consumption behavior if they can feel the extension of memory and emotional needs in artistic derivatives. Consumers contact the artistic beauty of original derivatives in a different way through purchasing derivatives, and then further extend the wonderful experience and meet emotional needs; meanwhile, derivatives can retain a beautiful memory and record the splendid life; it can be taken as gifts for us to bestow on others and show and narrate the wonderful experience to friends. It is the complete process of visiting and experiencing museums and at the same time has met people's experiential needs materially and psychologically [11]

\section{CONCLUSION}

Artistic derivatives are the recreation of art. It is related to the process that designers add personal emotions through understanding the original artworks, which will be redefined through design. The major reason why the derivative market at home is stagnant is that the positioning of derivative design is inaccurate. Designers fail to fully grasp the psychological needs of consumers for artistic derivatives in today's historical background. The emotional experience is of great importance in the psychological needs of derivative consumers. Besides, the emotional experience has always played a crucial guiding role from the design of derivatives, the whole process of 
derivative consumption and the final process of using and exchanging derivatives. Therefore, it is necessary to take the emotional experience of consumers as the highest guiding principle in all links of the design, manufacture and sales of artistic derivatives. Only in this way can we improve the market attractiveness and added value of artistic derivatives.

\section{REFERENCES}

[1] Gui Tao. Analysis on the Cost of Value Chain in the Cultural Industry and Derivative Development [J], Special Zone Economy, 2013 (04): 213 桂蹈.文化产业价值链成本面分析及衍生品开发 [J].特区经 济.2013(04):213.

[2] Wang Yu. Why Artistic Derivatives Cannot Be Popular [N], People's Daily. Apr. 4th, 2014 (15) 王钰. 艺术衍生品为何热不起来[N].人民日 报.2014年 04 月 04 日(15).

[3] Liu Jing, Sun Xianghong. What Determine the Holistic Experience of Users for Products [J], Advances in Psychological Science, 2011 (19): 94-106 刘静,孙向红.什么决定着用户对产品的完整体验[J].心理科学 进展.2011(19):94-106

[4] Zhang Chengzhong, Yang Jinzhong. Research on the Emotional Factors in Product Design [J], Enterprise's Technology Development, 2009 (28): 137 张成忠, 杨锦重. 产品设计中的情感因素研究 [J]. 企业技术开 发.2009(28): 137 .

[5] Zhao Kai. Influence of Emotional Experience on Social Cognition-The Embodiment of Emotional Factors in Design Cognition, Master's Thesis, Department of Applied Psychology, Jilin University, 2005, 1-13 赵凯.情感体验对社会认知的影响-设计认知中情感因素的体现.硕士 学位论文, 吉林大学应用心理学系, 2005 年, 1-13

[6] Zhu Xincheng. New Progress of the Research on Social Cognition Psychology [J], Psychological Dynamics, 2000 (08): 75 朱新秤.社会认 知心理学研究的新进展[J].心理学动态.2000(08):75.

[7] Ye Lang. Principles of Aesthetics [M], Beijing: Peking University Press, April 2009: 315 叶朗.美学原理[M].北京: 北京大学出版社, 2009 年 4 月:315.

[8] B. Joseph Payne, Experience Economy [M], Beijing: China Machine Press, May 2002: 18, 62 B. 约瑟夫.派恩.体验经济[M]. 北京: 机械工 业出版社，2002 年 5 月:18，62.

[9] Qian Zuyu, Xiong Jian. Analysis on the Characteristics of Tourists' Consuming Behaviors in the Era of Experience Economy [J], Marketing Strategy, 2007 (205) 钱祖爆, 熊 健. 体验经济时代的旅游者消费行为 特点分析[J].营销策略. 2007(205):

[10] Zhang Caihua. Understand Experience Economy and Consumption Economy from the Perspective of Consuming Behavior [J], 2005 (21): 88 张彩华.从消费行为的角度理解体验经济消费经济.消费经济 [J].2005(21):88

[11] Ma Lin. Research on the Development of Artistic Derivations in Museum [D], Master's Thesis of Nanjing University of the Arts, April 2013: 8-9 马琳.博物馆艺术衍生品开发研究[D].南京艺术学院硕士学 位论文，2013 年 4 月:8-9.

[12] Ma Chunyu. Design Aesthetics -Life Aesthetics and the Observation and Thinking on Artistic Derivatives - Conceptual Sketch about the Industrial Development of Artistic Derivatives [J], Culture Monthly, 2014 (09): 78 马春雨.设计美学-生活美学与艺术衍生的观与想-艺术 衍生品产业发展的观念性简述[J].文化月刊.2014(09):78.

[13] Shi Xiaodong. Discussion on the "Fuzzy Features" of the Brands of Costume Designers, Art and Design (Theory), 2012 (10), 106-108 史小 冬. 试论服装设计师品牌的 “模糊属性”. 艺术与设计（理 论）.2012(10).106-108.

[14] Susan Lange, Artistic Issues [M], Beijing: China Social Sciences Publishing House, June 1983: 92-105 苏珊.朗格.艺术问题[M].北京: 中国社会科学出版社，1983 年 6 月:92-105.

[15] Global Design Network. The Design of Chinese People's Daily Creative Kitchen Supplies, Dec.9th, $2014 \mathrm{http} / / / \mathrm{www} .70 . c 0 m /$ news/view-197089.html. 全球设计网.华人的日常创意㢄房用品设计.2014 年 12 月 9 日. http://www.70.com/news/view-19-7089.html. 